\title{
A New Bleeding Tendency Due to Hereditary Hyper $\alpha_{2}$-Macroglobulinemia
}

\author{
Yasuyuki Endo, Keiko Iwamoto, Shigeo Mamiya, \\ Hidetaka Niitsu, Toshiniro Itoh and Akira B. Miura \\ The Third Department of Internal Medicine, Akita \\ University School of Medicine, Akita 010
}

Endo, Y., Iwamoto, K., Mamiya, S., Nittsu, H., Iтoн, T. and Miura, A.B. $\quad A$ New Bleeding Tendency Due to Hereditary Hyper $\alpha_{2}$-Macroglobulinemia. Tohoku J. exp. Med., 1988, $\mathbf{1 5 4}(4), 365-373-\mathrm{A}$ heritable elevation in $\alpha_{2}$ macroglobulin $\left(\alpha_{2} \mathrm{M}\right)$ was identified in a 9-year-old girl with a severe bleeding tendency and activated partial thromboplastin time (APTT) prolonged to $49.1 \mathrm{sec}$ (normal 27-38) as well as recalcification time prolonged to $438 \mathrm{sec}(<180)$. The addition of her plasma to normal plasma made APTT prolong from 26.8 to $38.3 \mathrm{sec}$. The plasma $\alpha_{2} \mathrm{M}$ levels in her relatives were checked, i.e., proband, her sister, mother, maternal grandmother, father, and paternal grandmother: Their levels were $406,380,352,339,166$ and $236 \mathrm{mg} / 100 \mathrm{ml}(140-285)$, respectively. Thus the patient's condition was thought to be an autosomal dominant disease, though her other relatives displayed no apparent clinical symptoms. Of significance was that a possible causal association between her elevated $\alpha_{2} \mathrm{M}$ and her prolonged APTT was indicated. The activity of the $\alpha_{2} \mathrm{M}$, determined as trypsin-protein esterase, was $351 \mathrm{mg} / 100 \mathrm{ml}(197 \%)$. The $\alpha_{2} \mathrm{M}$ also demonstrated normal horizontal mobility to anti- $\alpha_{2} \mathrm{M}$ plasma with a high precipitin arc (showing the difference of the protein concentration) by crossed immunoelectrophoresis, and a normal horizontal mobility of immunofixation electrophoresis. In addition, after analysis of testing done by SDS-polyacrylamidegelelectrophoresis, we found no qualitative abnormality in the $\alpha_{2} \mathrm{M}$ of the patient. — prolonged APTT; elevation of $\alpha_{2}$ macroglobulin; autosomal dominant; no qualitative abnormalities

Alpha 2 macroglobulin $\left(\alpha_{2} M\right)$ is a plasma protein with a wide spectrum of enzyme inhibition capabilities, having a molecular weight of about 725,000 daltons (Collen 1981; Mammen 1983). Congenital $\alpha_{2} \mathrm{M}$ deficiency is a rare disorder that has been described only four times in the literature (Mahour et al. 1978 ; Bergqvist and Nilsson 1979 ; Stenbjerg 1979 ; Branson et al. 1984). Generally speaking, this disease is not complicated with clinical symptoms, but in our last article(Branson et al. 1984) we reported on a case with arterial thrombosis $\left(\alpha_{2}\right.$ M deficiency Irvine) and pointed out the possibility of hyper $\alpha_{2}$ macroglobulinemia. Recently, we experienced the first case of a bleeding tendency probably due to hereditary hyper $\alpha_{2}$ macroglobulinemia that prolonged both activated partial thromboplastin time (APTT) and recalcification time. 
Further study by immunoelectrophoresis and SDS-polyacrylamidegelelectrophoresis (PAGE) demonstrated no qualitative abnormality in the $\alpha_{2} \mathrm{M}$, of the patient.

\section{Case Report}

In September 1985, a 9-year-old girl came to our hospital for treatment of recurrent severe nasal bleeding that began when she was six. She had no past history of intramuscular or intraarticular bleeding or purpura, and no evidence of consanguinity was found in the last three generations of her family, although there was a high predisposition to cancer on the mother's side (Fig. 1). A physical examination, including the nasal cavity of the patient, revealed no abnormalities. Her immunoglobulin ( $\mathrm{Ig}$ ) M was elevated to $246 \mathrm{mg}$ / $100 \mathrm{ml}$ (normal 50-200) and serum alkaline phosphatase to $809 \mathrm{U} / \mathrm{l}(80-240)$, and her liver and renal functions were within normal limits. Her complement system was normal as well.

\section{Materials And Method}

Nine volumes of blood were drawn into one volume of $3.8 \%$ trisodium citrate and platelet-rich plasma (PRP) was prepared by centrifuging blood at $200 \mathrm{~g}$ for $10 \mathrm{~min}$ at room temperature for platelet function determination. After removing PRP, the blood was further centrifuged at $2000 \mathrm{~g}$ for $5 \mathrm{~min}$ at room temperature to obtain platelet-free plasma (PFP). PFP was used within two hr for the study of coagulation and fibrinolysis. Plasma for the determination of prostaglandin products was anticoagulated by disodium ethylendiamine tetraacetic acid (EDTA-2Na) + indomethacine+kallikrein, and plasma to determine $\beta$-thromboglobulin and platelet factor 4 was anticoagulated by EDTA-2Na + theophyllin.

Platelet function and coagulation studies were then performed, primarily using standard methods (Biggs 1976). FactorVIII related antigen (FVIIIR: Ag) was determined by Laurell's method (Laurell 1966). von Willebrand factor was ascertained by the washed platelet method (Weiss et al. 1973) and multimeric composition by sodium dodecylsulphate (SDS)-agarose gel electrophoresis (Ruggeri and Zimmerman 1980). Prekallikrein and high molecular weight (HMW)-kininogen were determined by the substrate deficient assay (SRL, Tokyo), and native inhibitors by the single radial immunodifusion method (Behringwerke, Marburg, FRG). The $\alpha_{2}$ M was analyzed by crossed immunoelectrophoresis (Ganrot 1972) and by immunofixation electrophoresis (Alper and Jonson 1969) for anti- $\alpha_{2} \mathrm{M}$ plasma (Hoechst, Frankfurt, FRG), The activity of the $\alpha_{2} \mathrm{M}$ was assayed as esterolytic activity using a substrate (Ganrot 1966). For the qualitative analysis of $\alpha_{2} \mathrm{M}$, western blotting was done to the nitrocellulose membrane after all the plasma protein was differentiated by SDS-polyacrylamide gel electrophoresis (PAGE). The $\alpha_{2} \mathrm{M}$ was dyed by 3 amino-9ethylcarbazole (AEC, Nakarai Chem., Tokyo) after treatment with anti-human $\alpha_{2} \mathrm{M}$, swine antirabbit Ig and soluble horseradish peroxidase anti-horseradish peroxidase complex (PAP; Hoechst). Commercial $\alpha_{2}$ M (Sigma Chemical Co., St. Louis, MO, USA) used to study the relationship between $\alpha_{2} \mathrm{M}$ and APTT was diluted by physiological saline and was added to standard plasma half and half on determination of APTT. Fibrinopeptides were then evaluated by sensitive radio immunoassay (Ohno 1983). Protein $\mathrm{C}$ was determined by enhanced Laurell analysis (Griffin et al. 1981). Fibronectin was also ascertained by Laurell's method.

Platelet size and count were determined with ELT-8 (Ortho Diagnostic System, Westwood, MA, USA). Platelet adhesiveness was measured with a glass bead filter, modified by one of the authors (Endo 1974), and the aggregation was measured with a Lumi-aggregometer (Chrono-Log, Havertown, PA, USA). Platelet factor $3\left(\mathrm{PF}_{3}\right)$ was determined by the kaolin-clotting method (Hardisty and Hutton 1965) and by the kaolin- 


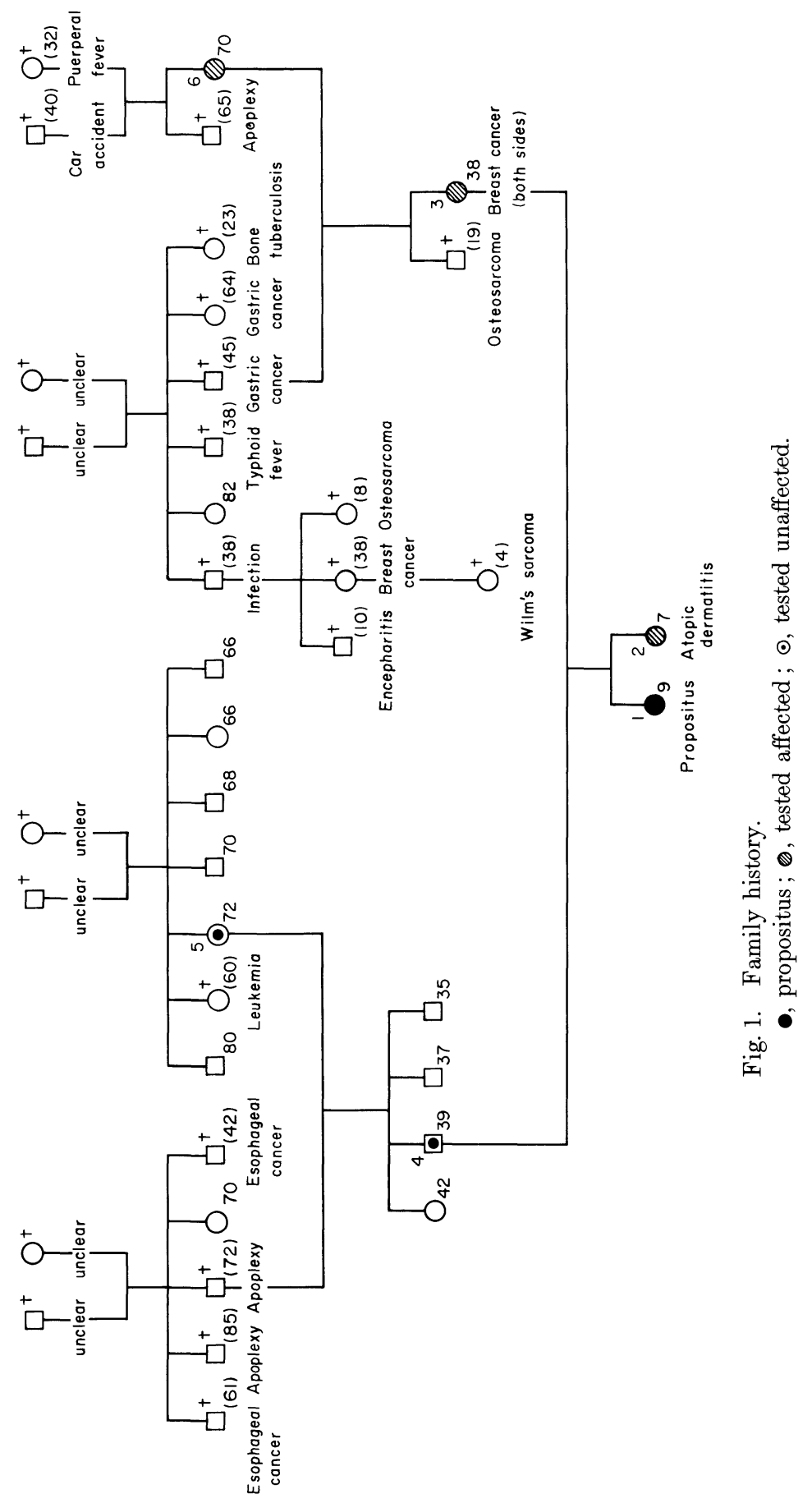


Russel's viper venom method (Spaet and Cintron 1965). Thromboxane $\mathrm{B}_{2}$ and 6-keto $\mathrm{PGF}_{1} \alpha$ in plasma were measured by the RIA method (New England Nuclear, Boston, MA, USA) (Watanabe 1983). $\beta$-Thromboglobulin ( $\beta$-TG) (Amerssham, Buckinghamshire, England) and platelet factor $4\left(\mathrm{PF}_{4}\right)$ (Abbott Laboratory, North Chicago, IL, USA) were ascertained by the RIA method (Endo et al. 1981).

TABLE 1. Study of coagulation and fibrinolysis

\begin{tabular}{|c|c|c|}
\hline & Patient & Normal \\
\hline $\mathrm{PT}(\mathrm{sec})$ & 11.1 & $11 \sim 15$ \\
\hline APTT (sec) & $49.1^{*}$ & $27 \sim 38$ \\
\hline Recalcification time & $438^{*}$ & $<180$ \\
\hline Fibrinogen $(\mathrm{mg} / 100 \mathrm{ml})$ & 235.9 & $170 \sim 400$ \\
\hline Cryofibrinogen & $(-)$ & $(-)$ \\
\hline Factor II activity (\%) & 100 & $50 \sim 200$ \\
\hline $\begin{array}{ll}\mathrm{V} & (\%)\end{array}$ & 105 & $50 \sim 200$ \\
\hline VII $\quad(\%)$ & 110 & $50 \sim 200$ \\
\hline VIII & 88 & $50 \sim 200$ \\
\hline $\mathrm{XI}$ & 75 & $50 \sim 200$ \\
\hline$(\%)$ & 75 & $50 \sim 200$ \\
\hline $\mathrm{XI} \quad(\%)$ & 135 & $50 \sim 200$ \\
\hline$(\%)$ & 60 & $50 \sim 200$ \\
\hline XIII $\quad(\%)$ & 90 & $50 \sim 200$ \\
\hline Factor VIII R: AG (\%) & 134 & $50 \sim 150$ \\
\hline von Willebrand factor (\%) & 100 & $70 \sim 120$ \\
\hline Multimeric composition & Normal & \\
\hline Prekallikrein $(\%)$ & 70 & $58 \sim 155$ \\
\hline HMW-kininogen $(\%)$ & 77 & $63 \sim 146$ \\
\hline Euglobulin clot lysis time (min) & 240 & $>180$ \\
\hline Plasminogen $(\%)$ & 80 & $75 \sim 125$ \\
\hline $\mathrm{FDP}(\mu \mathrm{g} / \mathrm{ml})$ & 2 & $<16$ \\
\hline $\mathrm{EPA}(\mathrm{mg} / \mathrm{ml})$ & 0.5 & $0.5 \sim 2.0$ \\
\hline $\mathrm{EPB}_{\beta 15-42}(\mathrm{mg} / \mathrm{ml})$ & 5.6 & $0.7 \sim 4.8$ \\
\hline D-dimer $(\mathrm{ng} / \mathrm{ml})$ & 65 & $<150$ \\
\hline Antithrombin III (mg/100 ml) & 104 & $79 \sim 121$ \\
\hline$\alpha_{1}$-Antytrypsin $(\mathrm{mg} / 100 \mathrm{ml})$ & 239 & $148 \sim 317$ \\
\hline $\mathrm{C}_{1}-\mathrm{INH}(\mathrm{mg} / 100 \mathrm{ml})$ & 14.7 & $14 \sim 30$ \\
\hline$\alpha_{2}$-Plasmin inhibitor $(\%)$ & 107 & $85 \sim 115$ \\
\hline$\alpha_{2}$-Macroglobulin $(\mathrm{mg} / 100 \mathrm{ml})$ & $406^{*}$ & $140 \sim 285$ \\
\hline Protein C $(\%)$ & 79 & $69 \sim 134$ \\
\hline Fibronectin $(\mu \mathrm{g} / \mathrm{ml})$ & 370 & $250 \sim 460$ \\
\hline Circulating anticoagulant & $(-)$ & $(-)$ \\
\hline
\end{tabular}




\section{Results}

Prothrombin time was normal. Activated partial thromboplastin time (APTT) and recalcification time were both prolonged, but the deficiencies of isolated coagulation factors including von Willebrand factor, prekallikrein, or HMW-kininogen were not observed (Table 1). Abnormal fibrinolysis was not provoked. Protein $\mathrm{C}$ and fibronectin were within normal limits and circulating anticoagulant was not detected. However, only in the native inhibitors was the level of $\alpha_{2} \mathrm{M}$ remarkably high. In the study of platelet function, a tendency to a slightly increased adhesiveness and aggregation, a decrease of factor 3 (Hardisty and Hutton 1965) and a prolonged reaction time (r) of thrombelastogram were

TABLE 2. Study of platelet function

\begin{tabular}{|c|c|c|}
\hline & Patient & Normal \\
\hline Bleeding time (Duke) (sec) & 150 & $60 \sim 180$ \\
\hline Capillary fragility $(-300 \mathrm{mmHg}$ ) (pieces) & 1 & $<30$ \\
\hline \multicolumn{3}{|l|}{ Platelets } \\
\hline Counts $\left(\times 10^{4} / \mu \mathrm{l}\right)$ & 23.9 & $11.7 \sim 32.9$ \\
\hline Mean corpuscle size & 2.0 & $1.0 \sim 5.0$ \\
\hline Adhesiveness (modified Hellem II) (\%) & 79.7 & $53.7 \pm 15.9$ \\
\hline \multirow{3}{*}{$\begin{aligned} \text { Aggregation } & (\mathrm{ADP} 4 \mu \mathrm{M})(\%) \\
& (\text { Collagen } 4 \mu \mathrm{g} / \mathrm{ml})(\%) \\
& (\text { Ristocetin } 1.2 \mathrm{mg} / \mathrm{ml})(\%)\end{aligned}$} & 87.0 & $40 \sim 80$ \\
\hline & 91.0 & $40 \sim 80$ \\
\hline & 91.0 & $40 \sim 80$ \\
\hline Thromboxane $B_{2}(\mathrm{pg} / \mathrm{ml}$ plasma $)$ & 588 & $<604$ \\
\hline 6 -Keto-PG-F ${ }_{1 \alpha}(\mathrm{pg} / \mathrm{ml}$ plasma $)$ & 23 & $21 \sim 260$ \\
\hline Factor 4 (ng/ml plasma) & 4.8 & $5.0 \pm 3.0$ \\
\hline$\beta$-Thromboglobulin (ng/ml plasma) & 13.0 & $13.2 \pm 5.6$ \\
\hline \multirow{2}{*}{$\begin{aligned} \text { Factor } 3 & \text { (Hardisty \& Hutton) }(\%) \\
& \text { (kaolin-Stypven) (sec) }\end{aligned}$} & $12.3^{*}$ & $>25$ \\
\hline & 13.2 & $14 \sim 31$ \\
\hline Clot retraction $(\mathrm{min})$ & 60 & $30 \sim 60$ \\
\hline \multirow{3}{*}{$\begin{array}{lll}\text { Thrombelastagram } & \mathrm{r} & (\min ) \\
& \mathrm{K} & (\min ) \\
& \text { ma } & (\min )\end{array}$} & $17.5^{*}$ & $8.5 \sim 10.0$ \\
\hline & 7.0 & $5.0 \sim 7.5$ \\
\hline & 51.5 & $50 \sim 57$ \\
\hline
\end{tabular}

TABLE 3. $\quad \alpha_{2}$-Macroglobulin in reference family members

\begin{tabular}{lrcccccc}
\hline & Normal & Patient & Sister & Mother & Father & $\begin{array}{c}\text { Paternal } \\
\text { grandmother }\end{array}$ & $\begin{array}{c}\text { Maternal } \\
\text { grandmother }\end{array}$ \\
\hline $\begin{array}{l}\alpha_{2} \text {-Macro- } \\
\text { globulin } \\
\text { (mg/100 ml) }\end{array}$ & $\begin{array}{r}\text { m } 106 \sim 260 \\
\text { f } 140 \sim 285\end{array}$ & 406 & 380 & 352 & & & 339 \\
APTT (sec) & $27 \sim 38$ & 49.1 & 40.7 & 39.3 & 36.4 & 33.3 & \\
\hline
\end{tabular}




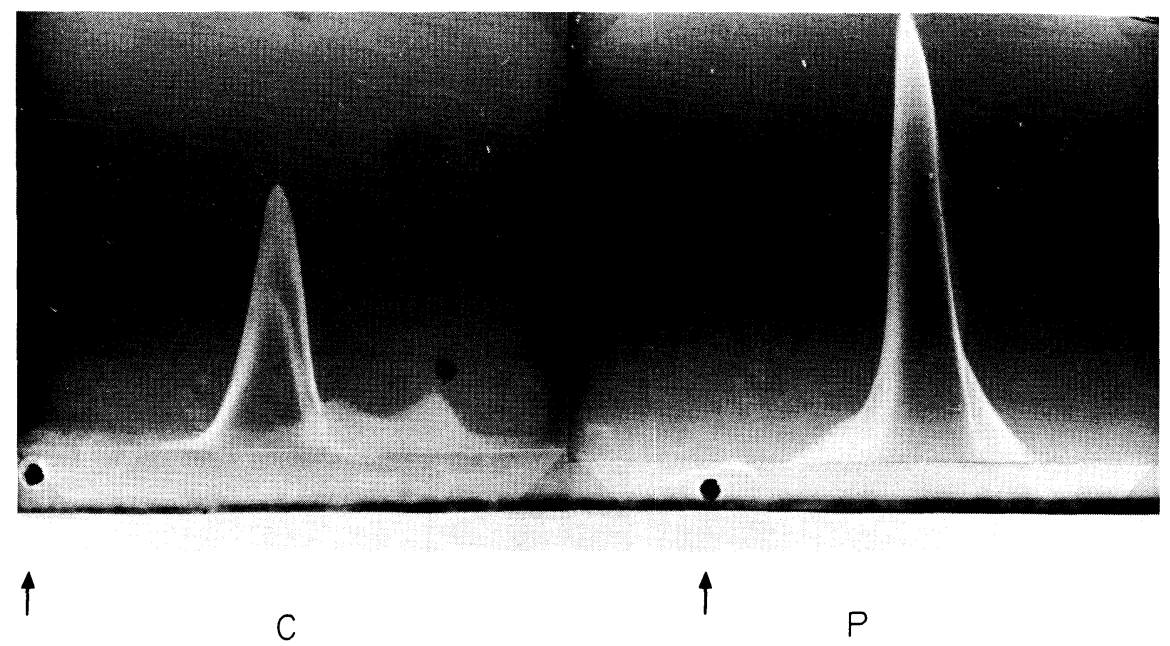

Fig. 2a. The immunoprecipitin of the patient's plasma $\alpha_{2}$-macroglobulin $(\mathrm{P})$ and normal plasma control (C) by crossed immunoelectrophoresis.

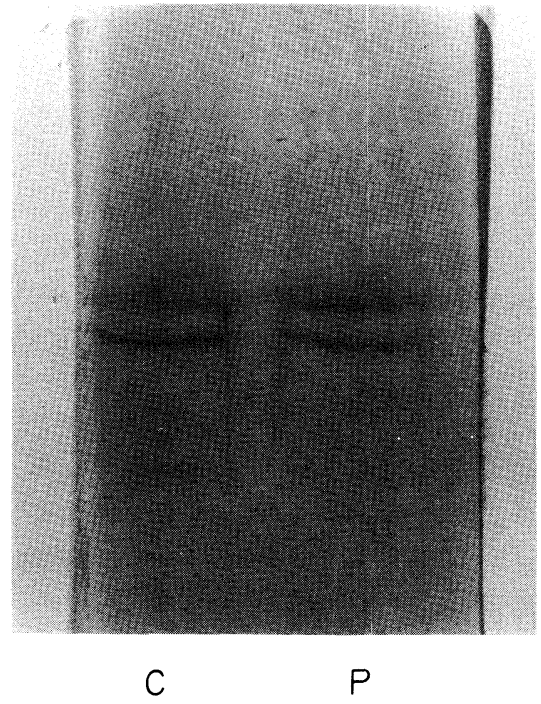

Fig. 2b. The immunoprecipitin of the patient's plasma $\alpha_{2}$-macroglobulin $(\mathrm{P})$ and normal plasma control $(\mathrm{C})$ by immunofixation electrophoresis.

observed. The last two abnormalities are probably due to the effect of abnormal plasma with a high $\alpha_{2} \mathrm{M}$, and the platelet function itself is thought to be almost normal (Table 2). Furthermore the added her plasma $(406 \mathrm{mg} / 100 \mathrm{ml}$ ) to normal plasma (200 mg/100 ml), half to half, let APTT prolong from $26.8 \mathrm{sec}$ to $38.3 \mathrm{sec}$.

Three generations of the patient's family were studied and her sister, mother, and grandmother were found to have $\alpha_{2} \mathrm{M}$ levels that ranged from 150 to 200 percent of normal (Table 3). The mobility of the proband's $\alpha_{2} \mathrm{M}$ for anti- $\alpha_{2} \mathrm{M}$ 


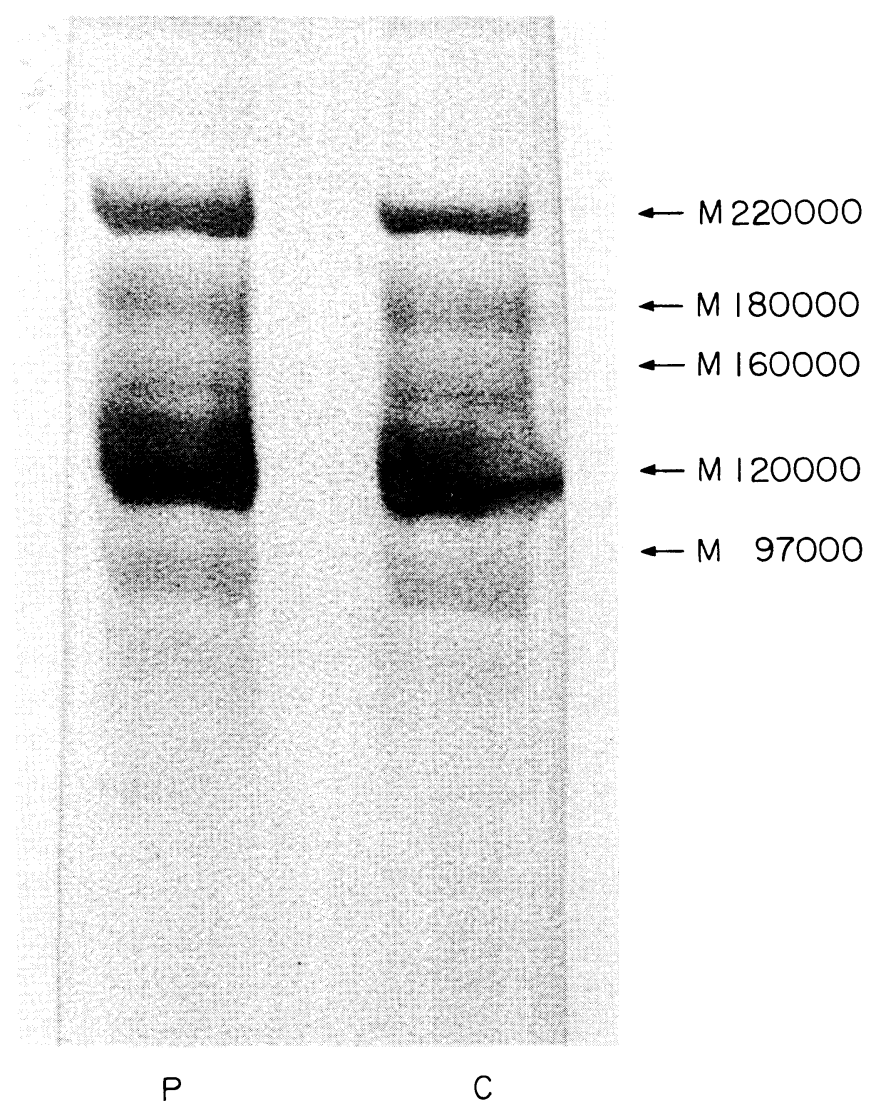

Fig. 3. No change was seen between patient's (P) and control's (C) $\alpha_{2}$ macroglobulin except the elevated absolute volume in a patient by SDS-polyacrlamide gel electrophoresis.

TABLE 4. Relationship between plasma concentration of $\alpha_{2}$-macroglobulin and APTT

\begin{tabular}{lccccccc}
\hline & Normal & Patient & Sister & Mother & Father & $\begin{array}{c}\text { Paternal } \\
\text { grandmother }\end{array}$ & $\begin{array}{c}\text { Maternal } \\
\text { grandmother }\end{array}$ \\
\hline $\begin{array}{l}\alpha_{2} \text {-Macro- } \\
\text { globulin } \\
\text { (mg/100 ml) }\end{array}$ & 50 & 100 & 150 & 200 & 250 & 300 & 350 \\
APTT (sec) & 38.6 & 40.3 & 41.9 & 43.3 & 44.3 & 48.0 & 54.3 \\
\hline
\end{tabular}

antigen was same when compared with the control, using crossed immunoelectrophoresis and immunofixation electrophoresis: However, crossed immunoelectrophoresis consistently disclosed a high precipitin arc (Fig. 2). The $\alpha_{2} \mathrm{M}$ activity as trypsin-protein esterase showed $351 \mathrm{mg} / 100 \mathrm{ml}$ (197 percent to normal). Plasma proteins could be differentiated by SDS-PAGE, but the mobility of the patient's plasma was the same as that of control plasma and the $\alpha_{2} \mathrm{M}$, dyed by PAP, showed no change in molecular weight when compared with the control, although the 
absolute volume of her $\alpha_{2} \mathrm{M}$ was more than that of the control's (Fig. 3). The diluted commercial $\alpha_{2} \mathrm{M}$ prolonged the APTT in relation to the absolute volume (Table 4). These volumes of $\alpha_{2} \mathrm{M}$ hardly changed plasmin and kallikrein, though $\alpha_{2} \mathrm{M}$ is said to make the effect to these substances.

\section{Discussion}

Although it is speculated that hyper $\alpha_{2}$-macroglobulinemia might exist (Branson et al. 1984), the discovery of a patient with a bleeding tendency due to a high plasma level of $\alpha_{2} \mathrm{M}$ is very important. Although it is said that $\alpha_{2} \mathrm{M}$ levels are raised in infants (Collen 1981), we should concentrate our mind on abnormally high level and inheritance of her $\alpha_{2}$ M. As determined by an electroimmunoassay, the movement of the $\alpha_{2} \mathrm{M}$ was normal, suggesting that the patient's $\alpha_{2} \mathrm{M}$ has no qualitative abnormality. Compared to an in vitro study, APTT of the patient might be more prolonged and her bleeding tendency might be more severe, but because of dilution by physiological saline in an in vitro study, the effect of $\alpha_{2} \mathrm{M}$ might be more strongly expressed without the interference of any other coagulation factor existing in the in vivo plasma. $\quad \alpha_{2} \mathrm{M}$ is said to potentially work more as an antithrombin than as antiplasmin or an antikallikrein (Mammen 1983), and our study now supports this theory. In addition, it is suggested that $\alpha_{2} \mathrm{M}$ is the major in vivo regulator of factor $\mathrm{Xa}$ (Fuchs and Pizzo 1983). The mode of transmission of the hyper $\alpha_{2}$-macroglobulinemia trait appears to be autosomal dominant. The reason why only the patient shows a bleeding tendency is not clear, but the highest level of $\alpha_{2} \mathrm{M}$ in plasma might have an influence on her symptoms. On the other hand, the relationship between hyper $\alpha_{2}$ macroglobulinemia and a high risk of cancer is difficult to explain. Atopic dermatitis with normal complement system might be concerned with because her sister has the same history as she. In addition, her high level of IgM is thought to be related with the high level of $\alpha_{2} \mathrm{M}$ and her high level of alkaline phosphatase is thought to be derived from the growing bones. To our knowledge, a bleeding tendency probably due to hereditary hyper $\alpha_{2}$-macroglobulinemia has not been reported. According to the early article (Branson et al. 1984) hypo $\alpha_{2}$ macroglobulinemia might bring about arterial thrombosis and our case would be described as a model without arteriosclerosis.

\section{Acknowledgments}

We would like to express our gratitude to Dr. Hoyu Takahashi of Niigata University for his determination of $\alpha_{2} \mathrm{M}$-activity.

\section{References}

1) Alper, C.A. \& Johnson, A.M. (1969) Immunofixation electrophoresis : A technique for the study of protein polymorphism. Vox Sang. (Basel), 17, 445-452.

2) Bergqvist, D. \& Nilsson, I.M. (1979) Hereditary $\alpha_{2}$-macroglobulin deficiency. 
Scand. J. Haemat., 23, 433-436.

3) Biggs, R. (1976) Human Blood Coagulation Haemostasis and Thrombosis, Blackwell Scientific, Oxford, pp. 657-750.

4) Branson, H.E., Endo, Y., Fagin, A.R. \& Schlutz, M. (1984) Heritable $\alpha_{2}$ macroglobulin deficiency in a patient with arterial thrombosis : $\alpha_{2}$-Macroglobulin deficiency Irvine. J. nat. med. Ass., 76, 1107-1112.

5) Collen, D. (1981) Natural inhibitors of haemostasis, with particular reference to firinolysis. In: Haemostasis and Thrombosis, edited by A.L. Bloom \& D.P. Thomas, Churchill Livingstone, Edinburgh, pp. 225-235.

6) Endo, Y. (1974) Studies on platelet adhesiveness. Acta haemat. jap., 37, 796-817.

7) Endo, Y., Mamiya, S., Satoh, M., Takahashi, K. \& Harada, T. (1981) Plasma $\beta$ thromboglobulin and platelet factor 4 in patients with chronic renal failure and effect of hemodialysis. Tohoku J. exp. Med., 135, 349-358.

8) Fuchs, H.E. \& Pizzo, S.V. (1983) Regulation of factor Xa in vitro in human and mouse plasma and in vivo mouse. $J$. clin. Invest., 72, 2041-2049.

9) Ganrot, P.O. (1966) Determination of $\alpha_{2}$-macroglobulin as trypsin-protein esterase. Clin. chim. Acta, 14, 493-501.

10) Ganrot, P.O. (1972) Crossed immunoelectrophoresis. Scand. J. clin. Lab. Invest., 29, Suppl. 124, 39-41.

11) Griffin, J.H., Evatt, B., Zimmerman, T.S. \& Kleiss, A.J. (1981) Deficiency of protein C congenital thrombotic disease. J. clin. Invest., 68, 1370-1373.

12) Hardisty, R.M. \& Hutton, R.A. (1965) The kaolin clotting time of platelet rich plasma. Brit. J. Haemat., 2, 258-268.

13) Laurell, C.B. (1966) Quantitative estimation of proteins by electrophoresis in agarose gel containing antibodies. Analyt. Biochem., 15, 45-52.

14) Mahour, G.H., Song, M.K., Adham, N.F. \& Rinderknecht, H. (1978) $\alpha_{2}$ Macroglobulin deficiency in a patient with Ehlers-Danlos syndrome. Pediatrics, 61, 894-897.

15) Mammen, E.F. (1983) Inhibitor abnormalities. Semin. Thrombos. Hemost., 9, 4248.

16) Ohno, Y. (1983) Simple and sensitive radio immunoassay of fibrinopeptide B $\beta 15-42$. Thrombos. Haemost., 50, 300.

17) Ruggeri, Z.M. \& Zimmerman, T.S. (1980) Variant von Willebrand's disease : Characterization of two subtypes by analysis of multimeric composition of factor VIII/von Willebrand factor in plasma and platelet. J. clin. Invest., 65, 1318-1325.

18) Spaet, T.H. \& Cintron, J. (1965) Studies on platelet factor 3 availability. Brit. J. Haemat., 2, 269-275.

19) Senbjerg, S. (1979) Inherited alpha 2 macroglobulin deficiency. Thrombos. Res., 22, 491-495.

20) Watanabe, Y. (1983) Radioimmunoassay for thromboxane $\mathrm{B}_{2}$. Spec. Ref. Lab., 7, 26-29.

21) Weiss, H.J., Hoyer, L.W., Richless, F.R., Verma, A. \& Rogers, J. (1973) Quantitative assay of a plasma factor deficient in von Willebrand's disease that is necessary for platelet aggregation-relationship to factor VIII procoagulant activity and antigen content. J. clin. Invest., 52, 2708-2716. 